\title{
Evaluation of the Savonius Wind Rotor Performance for Different External Overlap Ratios
}

\author{
Zied Driss, Ali Damak, Mohamed Salah Abid \\ Laboratory of Electro-Mechanic Systems (LASEM), National School of Engineers of Sfax (ENIS), University of Sfax, Sfax, Tunisia
}

Emails address:

zied.driss@enis.rnu.tn (Z.Driss),damak_ali@yahoo.fr(A. Damak), MohamedSalah.Abid@enis.rnu.tn (M. S. Abid)

To cite this article:

Zied Driss, Ali Damak, Mohamed Salah Abid. Evaluation of the Savonius Wind Rotor Performance for Different External Overlap Ratios. International Journal of Fluid Mechanics \& Thermal Sciences. Vol. 1, No. 1, 2015, pp. 14-19. doi: 10.11648/j.ijfmts.20150101.13

\begin{abstract}
Experimental investigations were carried out to study the external overlap ratios effect on the performance of a vertical axis wind rotor of the Savonius type. For thus, an open wind tunnel has been designed and realized in Laboratory of Electro-Mechanic Systems at National School of Engineers of Sfax. This involved also the instrumentation and the necessary equipment for the global characterization of the Savonius wind rotor. Particularly, this research required the setting up of four mounting characterized by different external overlap ratios. The overall performance evaluation of the rotor has been based on the power and dynamic torque coefficients in function of the air velocity speed measured in the test vein of the wind tunnel.
\end{abstract}

Keywords: Savonius Rotor, External Overlap, Performance Evaluation, Wind Tunnel

\section{Introduction}

A typical Savonius design consists of two vertical blades aligned with the rotating shaft. When compared with other wind turbine, the Savonius wind rotor offers lower performance in terms of power coefficient. Indeed, it offers a number of advantages as it is extremely simple to build, it is self-starting and it has no need to be oriented in the wind direction. Although it is well suited to be integrated in urban environment as mini or micro wind turbine it is inappropriate when high power is requested. For these reasons, several studies have been carried-out in recent years in order to improve its aerodynamic performance [1-13]. For example, D'Alessandro et al. [1] developed a mathematical model of the interaction between the flow field and the rotor blades. The aim of this research was to gain an insight into the complex flow field developed around a Savonius wind rotor and to evaluate its performance. They validated the model by comparing it with data obtained at Environmental Wind Tunnel (EWT) laboratory. Altan et al. [2] introduced a new curtaining arrangement to improve the performance of Savonius wind rotors. The curtain arrangement was placed in front of the rotor preventing the negative torque opposite to the rotor rotation. The geometrical parameters of the curtain arrangement were optimized to generate an optimum performance. The rotor with different curtain arrangements was tested out of a wind tunnel, and its performance was compared with that of the conventional rotor. The maximum power coefficient of the Savonius wind rotor is increased to about $38.5 \%$ with the optimum curtain arrangement. The experimental results showed that the performance of Savonius wind rotors could be improved with a suitable curtain arrangement. Irabu and Roy [3] improved and adjusted the output power of Savonius rotor under various wind power and suggests the method of prevention the rotor from strong wind disaster. The experiments include the static torque test of the fixed rotor at any phase angle and the dynamic torque test at rotation of them. Consequently, it was found that the maximum rotor rotational speed was achieved in the range of the guide-box area ratio between 0.3 and 0.7 and the value of the output power coefficient of the rotor with guide-box tunnel of the area ratio 0.43 increases about 1.5 times with three blades and 1.23 times with two blades greater than that without guide-box tunnel, respectively. It seemed that the performance of Savonius rotor within the guide-box tunnel is comparable enough with other methods for augmentation and control of the output. Saha et al. [4] conducted wind tunnel tests to assess the aerodynamic performance of single, two and three-stage Savonius rotor systems. Both semicircular and twisted blades have been used. A family of rotor systems has been manufactured with identical stage aspect ratio keeping the identical projected area of each rotor. Experiments were carried out to optimize the different parameters like number of stages, number of blades and geometry of the blade. A further attempt was made to investigate the performance of two-stage rotor system by inserting valves on the concave side of blade. 
Fujisawa [5] investigated the flow fields in and around Savonius rotors at various overlap ratios to clarify the effect of overlap on the flow mechanisms. Measurements of phase-averaged velocity distributions were carried out using particle imaging velocimetry with a conditional sampling technique, and the results were compared with numerical calculations by a discrete vortex method. The measured velocity distributions indicate clearly the effect of the overlap both on the flow through the overlap and on the formation region of the vortices downstream of the rotor. Although numerical calculations can predict the basic features of the variation of the flow field with rotor angle, the flow field of a stationary rotor, especially at small rotor angles, is not well reproduced in the calculations, suggesting that the assumptions of flow separation at the tips of the blades and the two-dimensionality of the flow are invalid. However, the correlation with measurement is improved for the flow over a rotating rotor. Al-Bahadly [6] determined and designd a suitable wind turbine which could be employed for rural homes or other small-scale applications. A variety of horizontal and vertical axis wind turbines exist, each possessing a number of advantages and disadvantages which needed to be taken into account before a basis for the design is selected. A small robust design which is relatively simple and cheap to construct is in essence the main criteria for wind turbine selection. A Savonius type rotor, which is a rotor based on a modification of the ' $\mathrm{S}$ ' rotor, is selected as it best fitted the design criteria. A small prototype $1.5 \mathrm{~m}$ tall with a rotor diameter of $0.65 \mathrm{~m}$ is designed and built. The finished prototype is used to estimate the power obtainable under normal operating conditions. Dobrev and Massouh [7] used CFD to study the behavior of a Savonius wind turbine under flow field conditions and to determine its performance and the evolution of wake geometry. The flow analysis helps to qualify the design of the wind turbine. They are making an experimental investigation in wind tunnel using PIV to validate simulations. There's investigation permits to determine the structure of the real flow and to access the quality of numerical simulations. Saha and Rajkumar [8] performed work on twist bladed metallic Savonius rotor and compared the performance with conventional semi-circular blades having no twist. They obtained an efficiency of 0.14 . Their rotor also produced good starting torque and larger rotational speeds. Saha et al. [9] conducted wind tunnel tests to assess the aerodynamic performance of single, two and three-stage Savonius rotor systems. Both semicircular and twisted blades have been used. A family of rotor systems has been manufactured with identical stage aspect ratio keeping the identical projected area of each rotor. Experiments were carried out to optimize the different parameters like number of stages, number of blades and geometry of the blade. Sabzevari [10] examined the effects of several ducting, concentrators and diffusers on the performance improvements of a split S Savonius rotor. A circularly ducted Savonius rotor equipped with a number of identical wind concentrators and diffusers along the periphery of circular housing produced efficiency of the order of $40 \%$. Damak et al.
[11] studied the aerodynamic behaviour of the helical Savonius rotors installed in an open jet wind tunnel. Tests determined the aerodynamic characteristics of the wind turbine. Particularly, they are interested on the power and torque coefficients. Driss and Abid [12] studied the aerodynamic characteristics on an open circuit tunnel. They are interested to verify that the test vein provides a uniform out flow, a high-speed and a low-turbulence. The comparison between the numerical results and the global experimental results confirms the validity of the numerical method. Driss et al. [13] studied the turbulent flow around a small incurved Savonius wind rotor. Experimental results are also conducted on an open wind tunnel to validate the numerical method.

On the bases of these studies, evaluation of the Savonius wind rotor performance has been reported based on the average produced power and exerted torque in the case of different external overlap ratios.

\section{Material and Method}

\subsection{Savonius Wind Rotor}

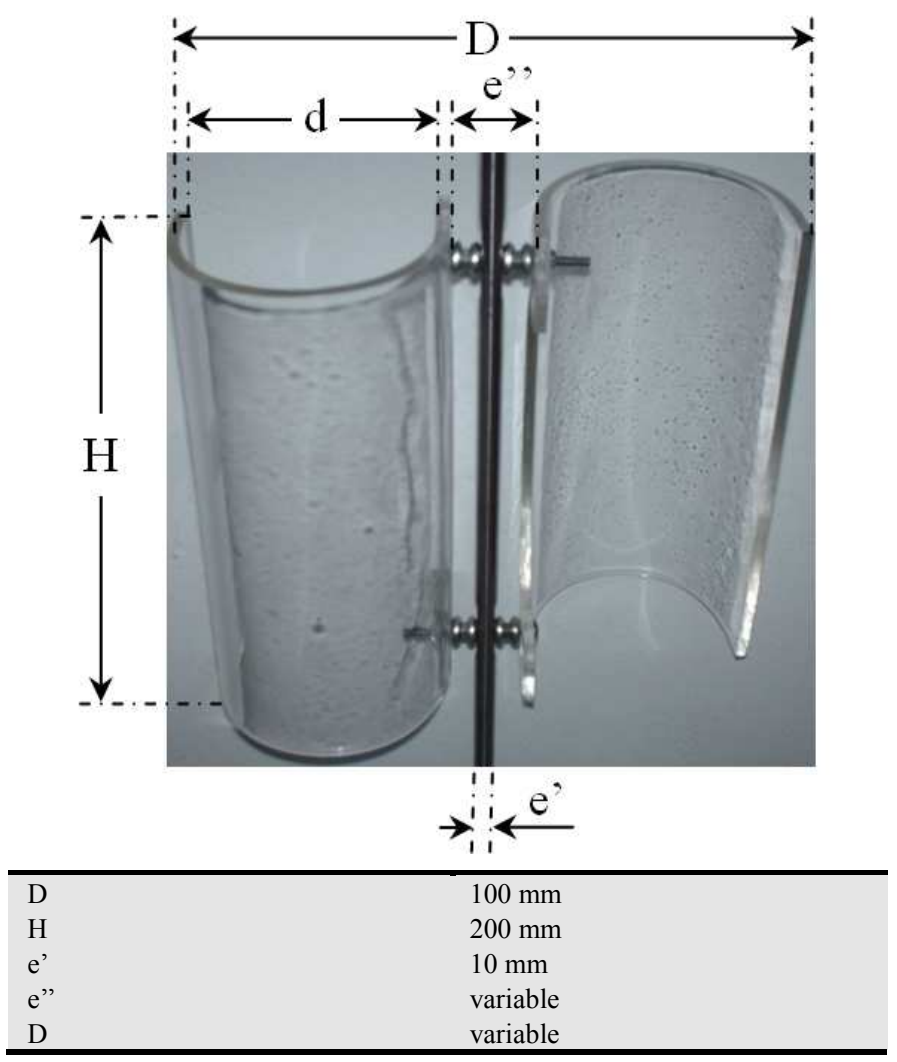

Figure 1. Geometrical arrangement.

The rotor at hand is a Savonius wind rotor made on Plexiglas (Figure 1). It is constituted by two half-cylindrical buckets characterized by the diameter $\mathrm{d}=100 \mathrm{~mm}$ and the height $\mathrm{H}=200 \mathrm{~mm}$. The buckets are collected on a common axis and are fixed within screws to make an angle equal to $180^{\circ}$. Indeed, the position between the two buckles is defined by the transversal distances designed by e". By introducing the shaft diameter $e^{\prime}=10 \mathrm{~mm}$, we can define the external 
overlap ratio (e"-e')/d. The study of the external overlap ratios effect on the Savonius wind rotor characteristics requires the e" distance change. In this investigation, we are interested in four mounting characterized by the external overlap ratios equal to $\left(\mathrm{e}^{\prime \prime}-\mathrm{e}^{\prime}\right) / \mathrm{d}=0, \quad\left(\mathrm{e}^{\prime \prime}-\mathrm{e}^{\prime}\right) / \mathrm{d}=0.1, \quad\left(\mathrm{e}^{\prime \prime}-\mathrm{e}\right) / \mathrm{d}=0.2 \quad$ and $\left(e^{\prime \prime}-e^{\prime}\right) / d=0.3$ (Figure 2 )

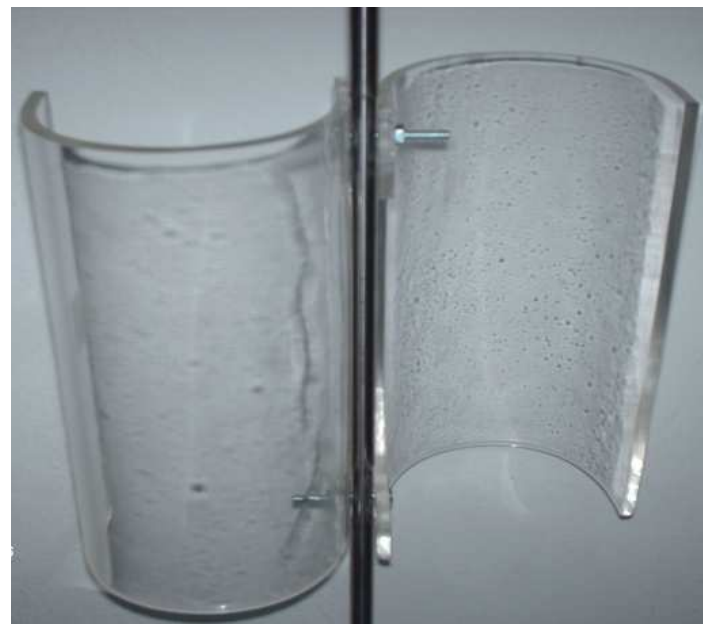

(a) $\left(\mathrm{e}^{\prime \prime}-\mathrm{e}^{\prime}\right) / \mathrm{d}=0$

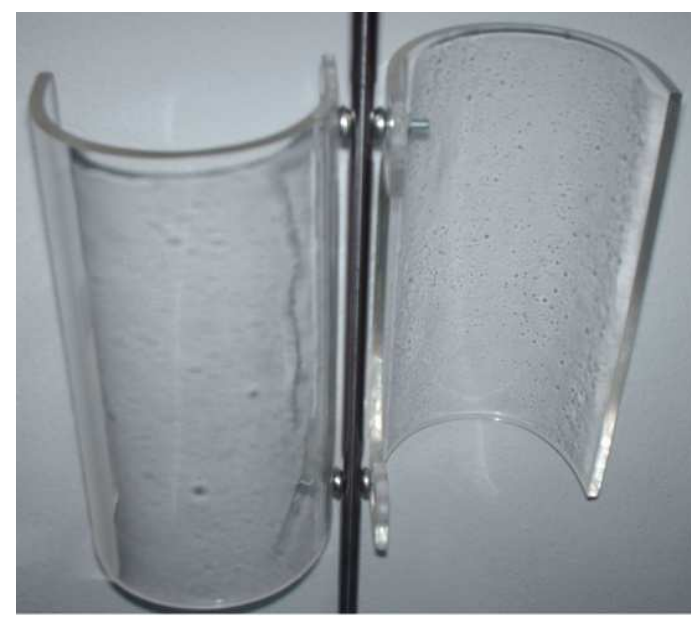

(b) $\left(\mathrm{e}^{\prime \prime}-\mathrm{e}^{\prime}\right) / \mathrm{d}=0.1$

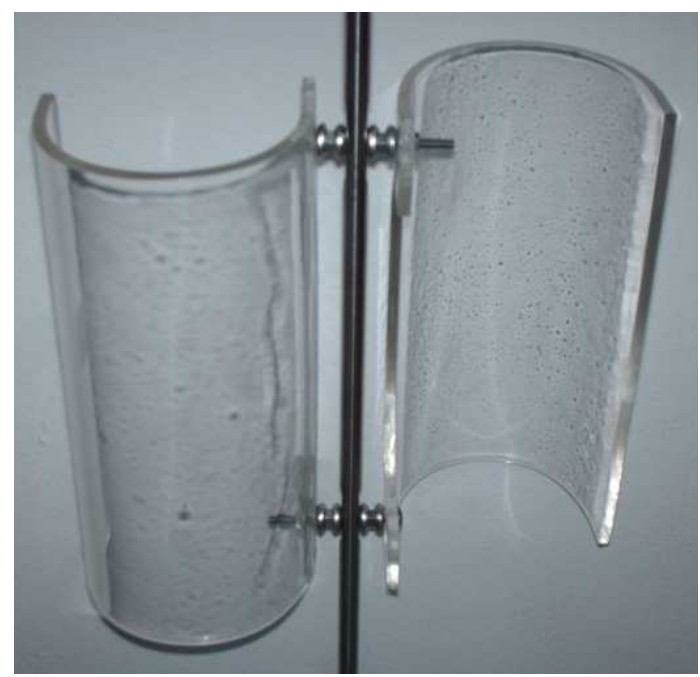

(c) $\left(e^{\prime \prime}-e^{\prime}\right) / d=0.2$

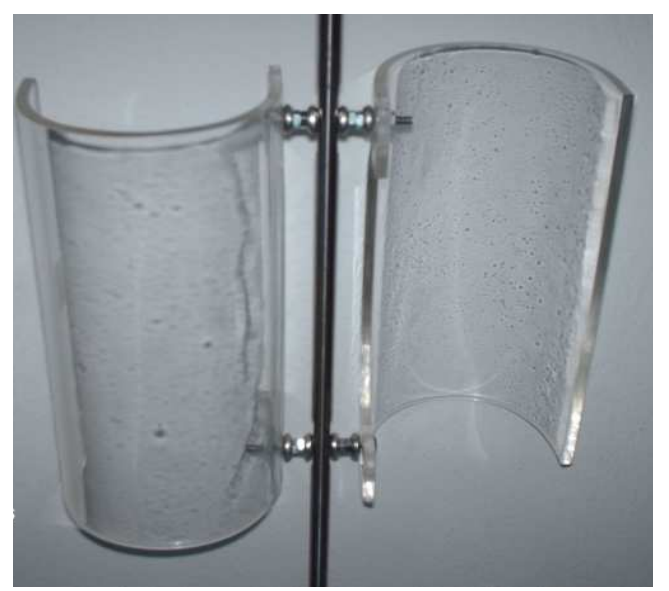

(d) $\left(e^{\prime \prime}-e^{\prime}\right) / d=0.3$

Figure 2. External overlaps.

\subsection{Wind Tunnel and Experimental Method}

Figure 3 shows the Savonius wind rotor placed in the middle of the wind tunnel test vein. The total length of the wind tunnel is $3857 \mathrm{~mm}$. This tunnel is a fairly simple device and it consists of five compartments: a settling chamber, a collector, a test vein, a diffuser and a drive section. The test vein is of $400 \mathrm{~mm}$ of width, $800 \mathrm{~mm}$ of length and $400 \mathrm{~mm}$ of height. By changing the rotation frequency of the vacuum cleaner SV0081C5-1F type, the wind tunnel exit-air velocity was controlled. The entire tests have been conducted within a hot wire anemometry AM-4204 model to measure the air velocity. In the test vein, the maximum air velocity value is equal to $12.7 \mathrm{~m} . \mathrm{s}^{-1}$. The rotational speed of the wind turbine rotor was measured with a digital tachometer CA-27 model. The dynamic torque exerted on the rotor shaft was measured with a DC generator which transforms the torque on its axis at an electrical current. For thus, the generator, coupled to the dynamometer RZR-2102 model, display simultaneously the shape speed and the dynamic torque. This dynamometer has been used to provide mechanical power to the generator which delivers an electric current in a resistive load.

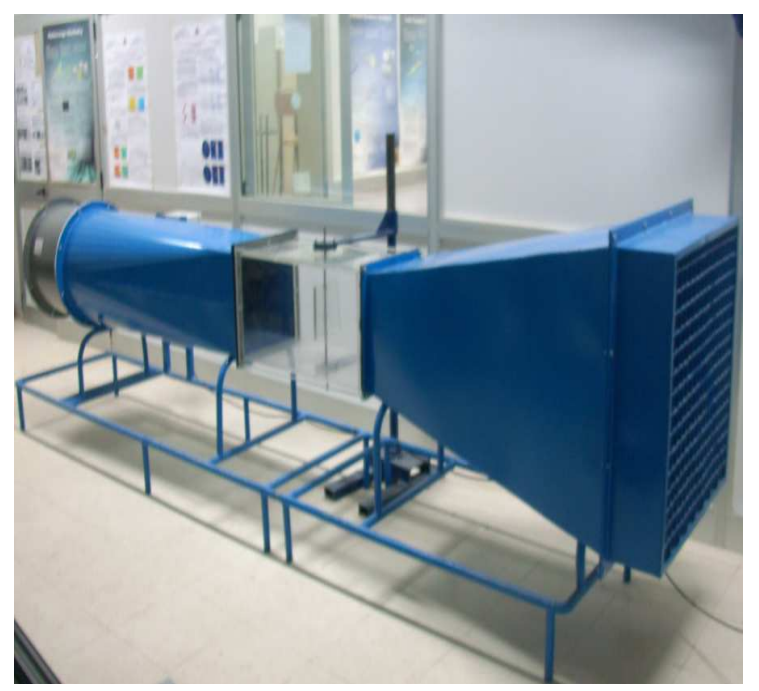

Figure 3. Wind tunnel. 


\section{Experimental Results}

\subsection{Power Coefficient}

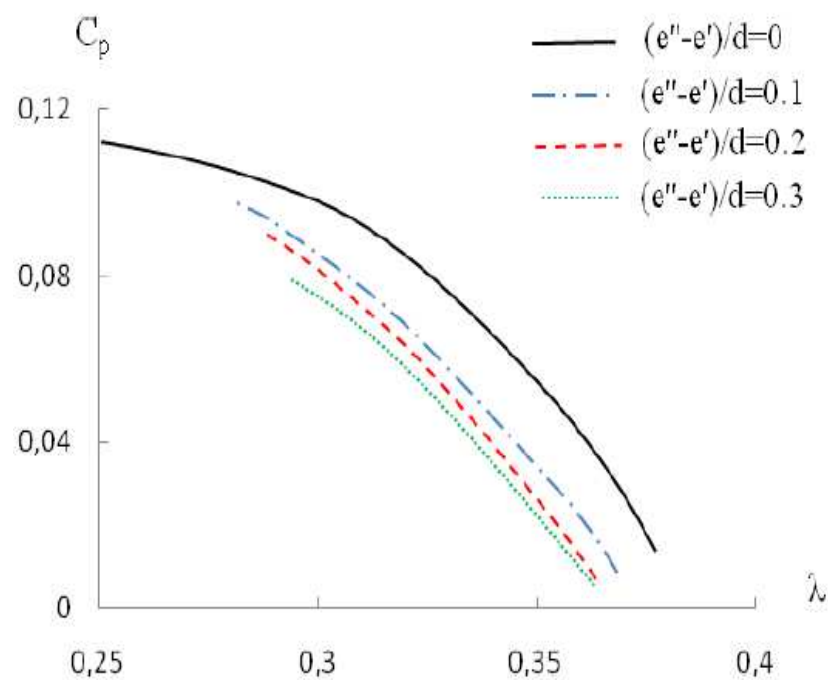

(a) $\mathrm{V}=8.8 \mathrm{~m} \cdot \mathrm{s}^{-1}$

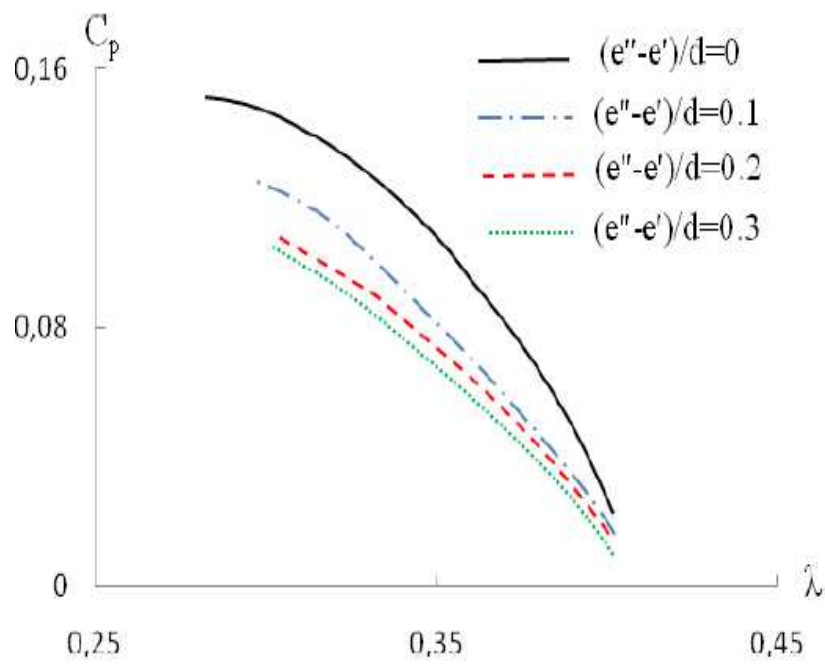

(b) $\mathrm{V}=9.95 \mathrm{~m} \cdot \mathrm{s}^{-1}$

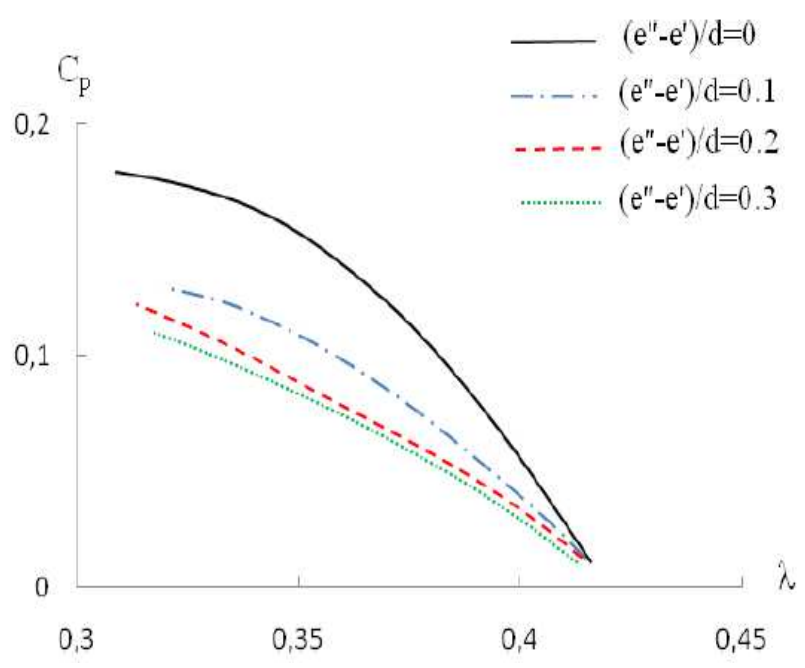

(c) $\mathrm{V}=11.15 \mathrm{~m} \cdot \mathrm{s}^{-1}$

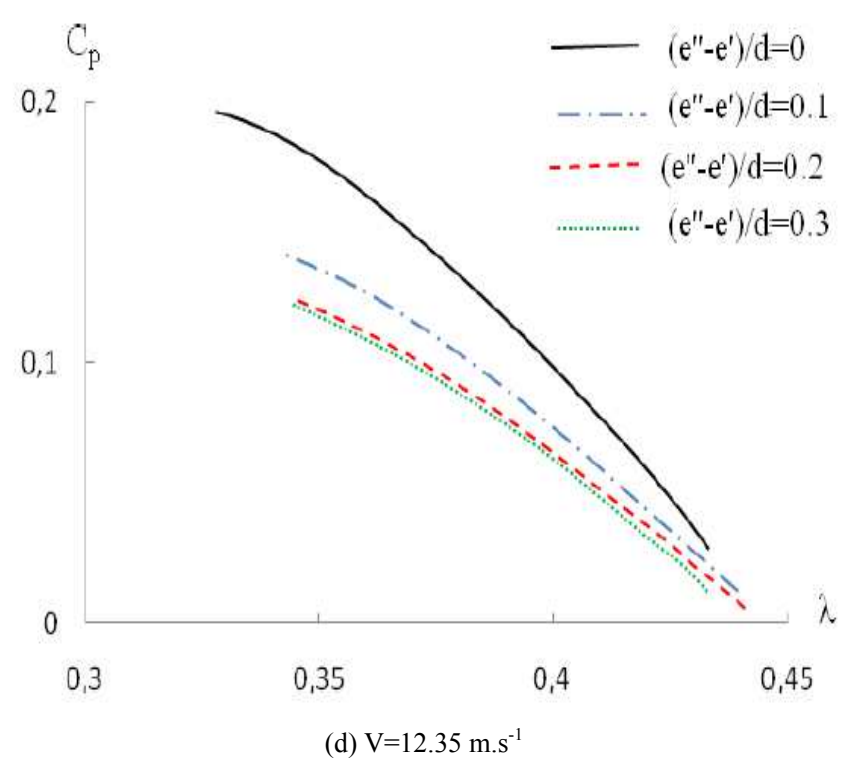

Figure 4. Variation of the power coefficient.

Figure 4 presents the variation of the power coefficient $C_{p}$ depending on the specific speed $\lambda$ of the Savonius wind rotor for different external overlaps equal to $\left(\mathrm{e}^{\prime \prime}-\mathrm{e}^{\prime}\right) / \mathrm{d}=0$, $\left(e^{\prime \prime}-e^{\prime}\right) / d=0.1,\left(e^{\prime \prime}-e^{\prime}\right) / d=0.2$ and $\left(e^{\prime \prime}-e^{\prime}\right) / d=0.3$ and for different wind speed values equal to $\mathrm{V}=8.8 \mathrm{~m} . \mathrm{s}^{-1}, \mathrm{~V}=9.95 \mathrm{~m} . \mathrm{s}^{-1}$, $\mathrm{V}=11.15 \mathrm{~m} . \mathrm{s}^{-1}$ and $\mathrm{V}=12.25 \mathrm{~m} . \mathrm{s}^{-1}$. In the case of the wind speed equal to $\mathrm{V}=8.8 \mathrm{~m} . \mathrm{s}^{-1}$, we have calculated the corresponding values of Reynolds number for the different external overlaps. These values are equal to $\mathrm{Re}=103000$, $\mathrm{Re}=108000, \mathrm{Re}=115000$ and $\mathrm{Re}=118000$ respectively. The increase of the Reynolds number values is due to the increase of the Savonius wind rotor diameter when the external overlap value between the two buckets increases. According to these results, it has been noted that the gotten curves present a parabolic pace. Therefore, these results show that the external overlap value has a direct effect on the presentation of the power coefficient values. Globally, it has been noted that the Savonius wind rotor power coefficient reaches the most important values for the external overlap value equal to $\left(e^{\prime \prime}-e^{\prime}\right) / d=0$. With the increase of the external overlap values, a progressive decrease of the power coefficient value has been observed. For the considered cases, it has been noted that the maximal value of the power coefficient is equal to $C_{p}=0.11$. It has been obtained with an external overlap value equal to $\left(e^{\prime \prime}-e^{\prime}\right) / d=0$ and a specific speed equal to $\lambda=0.25$. With the increase of the external overlap value, it has been noted that the power coefficient values decrease. Particularly, for the external overlap value $\left(e^{\prime \prime}-e^{\prime}\right) / d=0.3$ the power coefficient value becomes equal to $C_{p}=0.06$ for a specific speed equal to $\lambda=0.3$. For the other cases, these observations can be generalized.

\subsection{Torque Coefficient}

Figure 5 presents the variation of the torque coefficient $\mathrm{C}_{\mathrm{Md}}$ depending on the specific speed $\lambda$ of the Savonius wind rotor for different external overlaps equal to $\left(\mathrm{e}^{\prime \prime}-\mathrm{e}^{\prime}\right) / \mathrm{d}=0$, $\left(e^{\prime \prime}-e^{\prime}\right) / d=0.1,\left(e^{\prime \prime}-e^{\prime}\right) / d=0.2$ and $\left(e^{\prime \prime}-e^{\prime}\right) / d=0.3$ and for different 
wind speed values equal to $\mathrm{V}=8.8 \mathrm{~m} . \mathrm{s}^{-1}, \mathrm{~V}=9.95 \mathrm{~m} . \mathrm{s}^{-1}$, $\mathrm{V}=11.15 \mathrm{~m} . \mathrm{s}^{-1}$ and $\mathrm{V}=12.25 \mathrm{~m} \cdot \mathrm{s}^{-1}$. According to these results, it has been noted that the gotten curves present a parabolic pace. Therefore, these results show that the external overlap value has an effect on the presentation of the power coefficient values. Globally, it has been noted that the Savonius wind rotor torque coefficient reaches the most important values for the external overlap value equal to $\left(\mathrm{e}^{\prime \prime}-\mathrm{e}^{\prime}\right) / \mathrm{d}=0$. With the increase of the external overlap value, a progressive decrease of the torque coefficient value has been observed. In the case of the wind speed equal to $\mathrm{V}=8.8 \mathrm{~m} \cdot \mathrm{s}^{-1}$, it has been noted that the maximal value of the power coefficient is equal to $\mathrm{C}_{\mathrm{Md}}=0.45$. It has been obtained with an external overlap value equal to $\left(\mathrm{e}^{\prime \prime}-\mathrm{e} '\right) / \mathrm{d}=0$ and a specific speed equal to $\lambda=0.26$. With the increase of the external overlap value, it has been noted that the torque coefficient values decrease. Particularly, for an external overlap $\left(\mathrm{e}^{\prime \prime}-\mathrm{e}^{\prime}\right) / \mathrm{d}=0.3$, the torque coefficient value becomes equal to $\mathrm{C}_{\mathrm{Md}}=0.25$ for a specific speed equal to $\lambda=0.3$. For the other cases, these observations can be generalized.

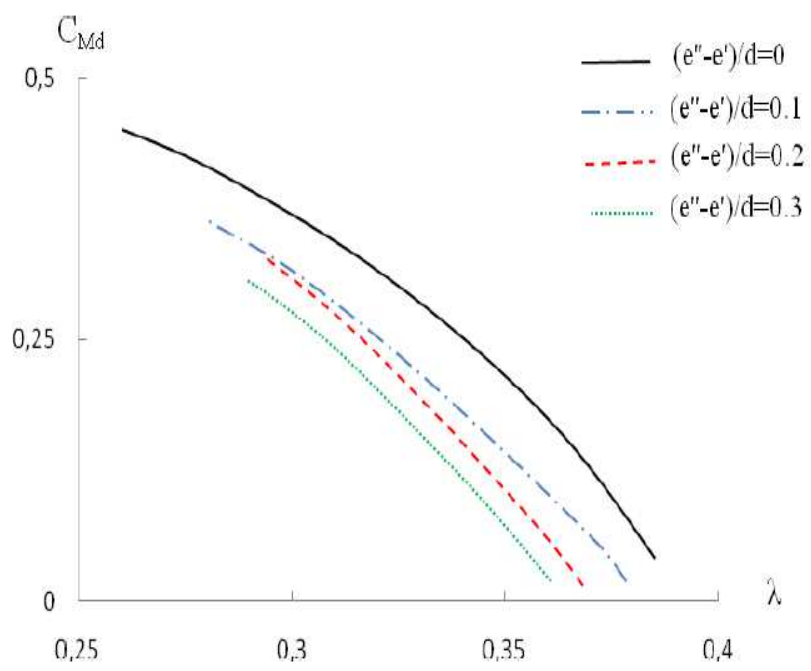

(a) $\mathrm{V}=8.8 \mathrm{~m} \cdot \mathrm{s}^{-1}$

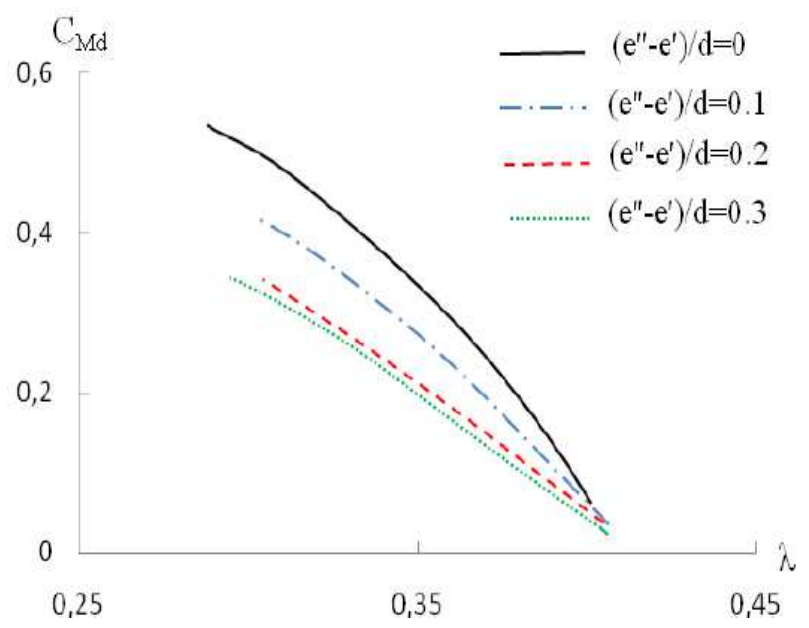

(b) $\mathrm{V}=9.95 \mathrm{~m} \cdot \mathrm{s}^{-1}$

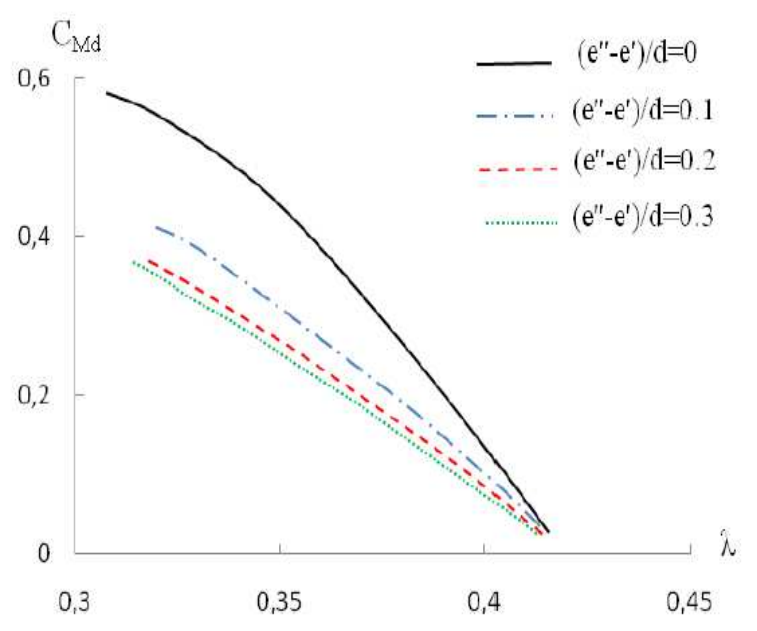

(c) $\mathrm{V}=11.15 \mathrm{~m} \cdot \mathrm{s}^{-1}$

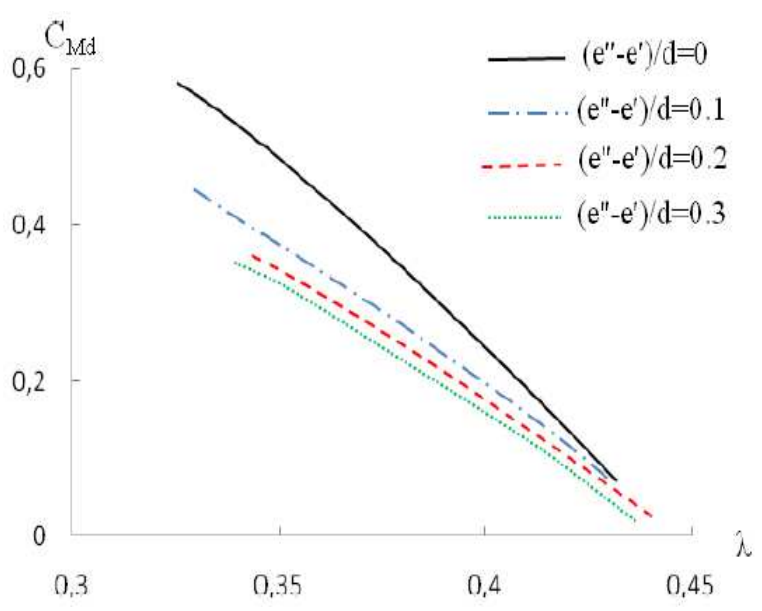

(d) $\mathrm{V}=12.35 \mathrm{~m} \cdot \mathrm{s}^{-1}$

Figure 5. Variation of the torque coefficient.

\section{Conclusion}

In this paper, we have studied the global characteristics of the Savonius wind rotor with different external overlap. Particularly, we have reported evaluating the overall performance of the rotor based on the power and torque produced. The goal of this work is to optimize and to improve the experimental conditions of the Savonius wind rotor. In fact, the wind energy consist an inexhaustible and advantageous renewable energy regarding mass production of the electric energy. It answers to a long-term energizing strategy that is based on the principle of the lasting development and the protection of the environment.

In the future, we propose to change others geometrical parameters to improve the Savonius wind rotor performance.

\section{References}

[1] D’Alessandro, V., Montelpare, S., Ricci, R., Secchiaroli, A., 2010, Unsteady Aerodynamics of a Savonius wind rotor: a new computational approach for the simulation of energy performance, Energy, 35, 3349-3363. 
[2] Altan, B.D., Atilgan, M., Özdamar, A., 2008, An experimental study on improvement of a Savonius rotor performance with curtaining, Experimental Thermal and Fluid Science, 32, 1673-1678.

[3] Irabu, K., Roy, J.N., 2007, Characteristics of wind power on Savonius rotor using a guide-box tunnel, Experimental Thermal and Fluid Science, 32, 580-586.

[4] Saha, U.K., Thotla, S., Maity, D., 2008, Optimum design configuration of Savonius rotor through wind tunnel experiments, Journal of Wind Engineering and Industrial Aerodynamics, 96, 1359-1375.

[5] Fujisawa, N., 1996, Velocity measurements and numerical calculations of flow fields in and around Savonius rotors, Journal of Wind Engineering and Industrial Aerodynamics, 59, $39-50$.

[6] Al-Bahadly, I., 2009, Building a wind turbine for rural home, Energy for Sustainable Development, 13, 159-165.

[7] Dobreva, I., Massouh, F., 2011, CFD and PIV investigation of unsteady flow through Savonius wind turbine, Energy Procedia, $6,711-720$.
[8] Saha UK, M. Jaya Rajkumar, On the performance analysis of Savonius rotor with twisted blades, Renewable Energy 31 (2006) 1776-1788.

[9] Saha, U.K., Thotla, S., Maity D., 2008, Optimum design configuration of Savonius rotor through wind tunnel experiments. Journal of Wind Engineering and Industrial Aerodynamics 96, 1359-1375.

[10] Sabzevari, A., 1978, Power augmentation in a ducted Savonius rotor, Second international symposium on wind energy systems, $1-6$.

[11] Damak, A., Driss, Z., 2013, Abid M.S., Experimental investigation of helical Savonius rotor with a twist of $180^{\circ}$, Renewable Energy, 52, 136-142.

[12] Driss, Z., Abid, M.S., 2012, Numerical and experimental study of an open circuit tunnel: aerodynamic characteristics, Science Academy Transactions on Renewable Energy Systems Engineering and Technology, 2 (1), 116-123.

[13] Driss, Z., Mlayeh, O., Driss, D., Maaloul, M, Abid, M.S., 2014, Numerical simulation and experimental validation of the turbulent flow around a small incurved Savonius wind rotor, Energy, 74, 506-517. 